\title{
Cognitive and Other Adverse Effects of Diphenhydramine Use in Hospitalized Older Patients
}

\section{Citation}

Agostini, Joseph V., Linda S. Leo-Summers, and Sharon K. Inouye. 2001. "Cognitive and Other Adverse Effects of Diphenhydramine Use in Hospitalized Older Patients." Arch Intern Med 161 (17) (September 24): 2091. doi:10.1001/archinte.161.17.2091.

\section{Published Version}

doi:10.1001/archinte.161.17.2091

\section{Permanent link}

http://nrs.harvard.edu/urn-3:HUL.InstRepos:33750338

\section{Terms of Use}

This article was downloaded from Harvard University's DASH repository, and is made available under the terms and conditions applicable to Other Posted Material, as set forth at http:// nrs.harvard.edu/urn-3:HUL.InstRepos:dash.current.terms-of-use\#LAA

\section{Share Your Story}

The Harvard community has made this article openly available.

Please share how this access benefits you. Submit a story.

\section{Accessibility}




\title{
Cognitive and Other Adverse Effects of Diphenhydramine Use in Hospitalized Older Patients
}

\author{
Joseph V. Agostini, MD; Linda S. Leo-Summers, MPH; Sharon K. Inouye, MD, MPH
}

Background: Diphenhydramine hydrochloride is a commonly prescribed medicine in hospitalized patients, but its adverse effects on older patients remain unclear.

Methods: We enrolled 426 hospitalized medical patients aged 70 years or older in a prospective cohort study in a university hospital. Measurements included baseline and daily assessments including Mini-Mental State Examination scores, Confusion Assessment Method ratings, direct observations for medical devices (urinary catheter or physical restraints), and blinded medical record extractions for diphenhydramine use.

Results: Of the 426 patients, 114 (27\%) received diphenhydramine during hospitalization and shared similar baseline characteristics including age, sex, delirium risk, and Mini-Mental State Examination scores compared with nonexposed patients. The diphenhydramineexposed group was at an increased risk for any delirium symptoms (relative risk [RR], 1.7; 95\% confidence interval $[\mathrm{CI}], 1.3-2.3)$ and for individual delirium symptoms, including inattention (RR, 3.0; 95\% CI, 1.5-5.9), disorganized speech (RR, 5.5; 95\% CI, 1.0-29.8), and altered consciousness (RR, 3.1; 95\% CI, 1.6-6.1). Exposed patients also had increased risk for urinary catheter placement (RR, 2.5; 95\% CI, 1.0-6.0) and longer median length of stay ( 7 vs 6 days; $P=.009$ ). A doseresponse relationship was demonstrated for most adverse outcomes. Overall, 24\% of diphenhydramine doses were administered inappropriately.

Conclusions: Diphenhydramine administration in older hospitalized patients is associated with an increased risk of cognitive decline and other adverse effects with a doseresponse relationship. Careful review of its use is necessary in this vulnerable population.

Arch Intern Med. 2001;161:2091-2097
From the Departments of Internal Medicine, (Drs Agostini and Inouye) and Epidemiology and Public Health (Ms Leo-Summers), and the Robert Wood Johnson Clinical Scholars Program (Dr Agostini), Yale University School of Medicine, New Haven, Conn.

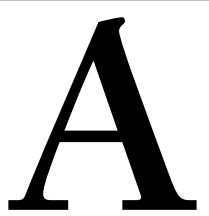

DVERSE DRUG reactions are a common iatrogenic complication in older hospitalized patients. ${ }^{1}$ Polypharmacy exacerbates the problem, ${ }^{2}$ as do inappropriate prescribing patterns, ${ }^{3}$ enhanced sensitivity to adverse effects due to age-related changes in pharmacodynamics and pharmacokinetics, ${ }^{4,5}$ and interactions among multiple, often new, medications. An important drugrelated iatrogenic outcome in the elderly is cognitive impairment. ${ }^{6,7}$ Drug-related cognitive impairment and delirium are particularly important in the inpatient setting, which represents an already vulnerable time because of the superimposition of acute illness and multiple drug use onto existent cognitive and medical comorbidities. In fact, the addition of a multiplemedication regimen during a hospital stay is an independent risk factor for delirium in older hospitalized patients. ${ }^{8}$

The use of medications with anticholinergic effects in particular leads to im- portant problems in older patients. ${ }^{9}$ Overall, these medications are associated with delirium more commonly than any other drug class. ${ }^{10}$ Other potential adverse effects include orthostasis, central nervous system depression, paradoxical excitement, visual disturbances, tachycardia, dry mouth, urinary retention, and constipation. ${ }^{11,12}$ Even mild disturbances in these cholinergic pathways can initiate a range of adverse effects that decrease an older patient's independence in functioning and ability to withstand the stressors of inpatient hospitalization.

Diphenhydramine hydrochloride, an antihistamine sedative drug with strong anticholinergic properties, is commonly prescribed in the elderly population. In an outpatient study of 850 elderly patients in intermediate-care facilities in Massachusetts, for example, more than one quarter were receiving some form of sedative and/or hypnotic medication, with diphenhydramine alone accounting for $26 \%$ of this total (14\%-41\% over all study sites). ${ }^{13}$ 


\section{PATIENTS AND METHODS}

\section{STUDY POPULATION}

We studied a prospective cohort consisting of consecutive admissions of older patients on a medicine service at YaleNew Haven Hospital (New Haven, Conn), a 900-bed urban teaching hospital serving the local community as well as a large referral base. All patients were admitted to the general medical service in a non-intensive care setting between March 1995 and February 1998. Patients were required to be 70 years or older with no baseline delirium. Exclusion criteria included profound dementia precluding verbal communication, hospital discharge or death within 48 hours of admission, and non-English speakers.

\section{ASSESSMENTS}

Trained clinician-researchers, blinded to study hypotheses and to patients' diphenhydramine use, carried out all assessments. Informed consent for participation was obtained from the patient or from a proxy (usually the closest relative) by procedures that were approved by the institutional review board of the Yale University School of Medicine, New Haven. All patients were screened within 48 hours of admission and data were collected on standardized forms. Research staff collected demographic and living situation information from the baseline interview followed by a cognitive evaluation consisting of a Folstein Mini-Mental State Examination (MMSE) ${ }^{21}$ and a Confusion Assessment Method (CAM) rating for delirium. ${ }^{22}$ Baseline delirium risk was defined according to a predictive model described previously. ${ }^{23}$ Researchers also reviewed charts to gather data on admission diagnoses and laboratory results, medical history, Charlson comorbidity scores ${ }^{24}$ and APACHE II
APACHE II (Acute Physiology and Chronic Health Evaluation II) scores. ${ }^{25}$ Thereafter, research staff carried out daily interviews to obtain MMSE and CAM ratings. They also observed the patient daily for addition of medical devices, such as a urinary catheter or physical restraints.

A separate researcher, blinded to the cognitive scores of each patient, extracted detailed information on diphenhydramine administration from the medical record, including dose, time, and frequency of administration, and documented indications and contraindications to determine those patients who had diphenhydramine exposure during hospitalization. Based on welldefined criteria, ${ }^{11}$ a contraindication was defined as 1 of the following processes documented in the medical record: angle-closure glaucoma, stenosing peptic ulcer, obstructive urinary symptoms, or allergy to diphenhydramine. Doses of diphenhydramine administered within 1 hour of each other were treated as 1 cumulative dose, with time of administration recorded as time of the first dose. Any patient receiving at least 1 dose of diphenhydramine was considered part of the diphenhydramine-exposed group.

\section{COGNITIVE OUTCOMES}

Evaluation of cognitive decline was determined using commonly accepted delirium symptoms in addition to standardized, validated instruments including the CAM rating for delirium and the MMSE score. Delirium symptoms were defined as the presence of any 1 of the 9 commonly accepted features of delirium: acute onset and fluctuating course, inattention, disorganized speech, altered level of consciousness, disorientation, memory impairment, perceptual disturbance, abnormal psychomotor activity, and an altered sleep-wake cycle. The CAM criteria for delirium
In the inpatient setting, fewer data are available on frequency of use. At our institution (an urban teaching hospital) approximately $15 \%$ of patients 70 years or older hospitalized on all services during a 10 -month period in 1999 received at least 1 dose of diphenhydramine during their hospital stay. Indications for diphenhydramine use include sedation, treatment of allergic reactions and vertigo, and prophylaxis for patients with prior transfusion reactions. Its potential adverse effects include those of the anticholinergic medications as noted above. We chose this drug to study because of its widespread use and its potential for substantial morbidity.

The current data about the effect of anticholinergic medications on cognitive function in the elderly are conflicting. Three prospective studies ${ }^{14-16}$ have shown no association between the use of anticholinergic drugs and delirium, while a prospective study of elderly patients treated for femoral neck fractures showed that anticholinergic drugs were a contributing factor for acute states of confusion. ${ }^{17}$ Small studies of older patients given diphenhydramine specifically have reported results ranging from a lack of sedative and cognitive effects (using visual analog scales, reaction times, verbal recall, and digitsymbol substitution $)^{18}$ to some degree of cognitive impairment (using verbal memory, visuospatial cognition, and Trails B testing $)^{19}$ to delirium in patients with mild dementia. ${ }^{20}$ Thus, further study is needed to clarify the effects of diphenhydramine use on cognitive outcomes as well as other adverse effects during hospitalization.

The specific aims of our present study are to examine the rate of diphenhydramine use in a large prospective cohort of elderly hospitalized patients; to evaluate potential adverse outcomes (eg, cognitive, behavioral, and other anticholinergic effects) associated with diphenhydramine use; and to describe current diphenhydramine use in the study cohort. Our underlying hypothesis is that diphenhydramine use results in an increased risk of adverse outcomes and that this risk will increase with the dose of diphenhydramine received.

\section{RESULTS}

A total of 426 patients were enrolled in the study (Table 1) with 114 patients (27\%) comprising the diphenhydramine-exposed group. The 2 cohorts shared similar sociodemographic characteristics, baseline delirium risk, and MMSE scores. There were no significant differences in baseline illness severity or comorbidity or report of sleep difficulty. The number of patients in either group who were exposed to other potentially psychoactive medications was likewise similar. Exposure to a psychotherapeutic medication during hospital- 
require the presence of acute onset and fluctuating course, inattention, and either altered level of consciousness or disorganized thinking. The CAM criteria provide a standardized delirium rating with a sensitivity of $94 \%$ to $100 \%$, a specificity of $90 \%$ to $95 \%$, and high interobserver reliability. ${ }^{22}$ Acute onset is not separately recorded because the development of these clinical features represents a change from the baseline admission status; that is, by definition any change during the daily assessments is considered an acute or new onset. For diphenhydramine-exposed patients, cognitive decline was required to occur within 48 hours of administration of any diphenhydramine dose. To meet CAM criteria, all criteria needed to be present at the same assessment. Delirium symptoms could arise at any time within 48 hours of the administration of any diphenhydramine dose. For all patients, the "at-risk" or exposure period was truncated at hospital day 12 to create comparable at-risk periods for the diphenhydramine-exposed and nonexposed groups, as well as to minimize the effects of long hospitalizations. This exposure period accounted for $84 \%$ of all patient-days. In addition, $94 \%$ of cases of delirium had occurred by hospital day 12 .

\section{DEFINITION OF VARIABLES}

During patient interviews, trained clinician-researchers used the following definitions in recording patient data. Inattention is defined as difficulty maintaining focus or being easily distracted during the interview. Disorganized speech is speech that is irrelevant, unclear, illogical, or unpredictable in subject matter. Altered consciousness is any state other than alert (normal), ranging from hypervigilant to lethargic, stuporous, or unarousable. Memory impairment is difficulty recalling basic instructions, prior interactions, or hospital events. Disorientation is misidentification of time of day, patient location (eg, responding with a nonhospital location), or personal hospital bed. Abnormal psychomotor activity includes psychomotor agitation (an increased level of motor activity) and retardation (decreased motor activity). Altered sleep-wake cycle refers to patients reporting increased frequency of nighttime awakening and daytime naps compared with baseline (admission) sleep history. Behavioral disturbance includes combative behavior, repeated unsafe behaviors (eg, climbing over bed rails), pulling at dressings or tubes, yelling, or swearing. The use of physical restraint indicates immobilization of the hands, feet, or chest with a restraining device during the patient interview. New urinary catheterization includes the use of indwelling (Foley) catheters either within 48 hours of diphenhydramine exposure or any time during hospitalization for patients not exposed to diphenhydramine.

\section{ANALYSIS}

Following standardized coding and entry of data, statistical analysis was completed using PC-based SAS software (SAS version 6.12; SAS Institute Inc, Cary, NC). Baseline characteristics and outcomes were compared with $\chi^{2}$ tests for binary measures and $t$ tests for continuous measures. Relative risks (RRs) were calculated with 95\% confidence intervals (CIs). The Mantel-Haenszel $\chi^{2}$ statistic was used to test for trends among categorical outcomes and 1-way analysis of variance was used for continuous outcomes across diphenhydramine-exposed and nonexposed groups. A logistic regression model was carried out with the outcome of delirium symptoms in the diphenhydramine-exposed group, controlling for baseline delirium risk, sex, and age. The odds ratios were calculated using 95\% CIs. ization (eg, an antidepressant or antipsychotic drug such as haloperidol) occurred in $16 \%$ of the diphenhydramineexposed patients and $13 \%$ of nonexposed patients $(P=.48)$, whereas exposure to an anxiolytic, sedative, or hypnotic drug other than diphenhydramine occurred in 39\% of the exposed and $31 \%$ of the nonexposed patients $(P=.08)$.

The presence of delirium symptoms was much more likely to occur in the diphenhydramine-exposed group than the nonexposed group (Table 2). There was a $70 \%$ increased risk of cognitive decline in the diphenhydramineexposed group (42\% of those exposed vs $24 \%$ of those not exposed [RR, 1.7; 95\% CI, 1.3-2.3; P<.05]). In addition, the diphenhydramine-exposed group was at significantly increased risk for inattention (RR, 3.0), disorganized speech (RR, 5.5), altered level of consciousness (RR, 3.1), abnormal psychomotor activity (RR, 2.3), altered sleep-wake cycle (RR, 2.0), and behavioral disturbance (RR, 5.6). New urinary catheter use occurred in $8 \%$ of the diphenhydramine-exposed group compared with $3 \%$ in the nonexposed group (RR, 2.5; 95\% CI, 1.0-6.0). Length of stay was significantly longer on average in the diphenhydramine-exposed group (median of 7 vs 6 days; $P=.009$ ).

In a multiple logistic regression model involving 423 observations (3 excluded for missing variables), the adjusted odds ratio for the risk of cognitive decline in the diphenhydramine-exposed group was 2.3 (95\% CI, 1.4-3.6). This result controlled for age, sex, and baseline delirium risk, none of which were independently statistically significant. These multivariable results confirm the bivariate analyses reported above.

An examination of dose-response relationships (Table 3) showed a significant trend toward increased cognitive decline with increasing diphenhydramine dosage for both delirium symptoms and the CAM or MMSE outcomes. Four delirium symptoms (inattention, altered consciousness, abnormal psychomotor activity, and altered sleep-wake cycle) showed significant doseresponse trends, as did length of stay outcomes.

Results from subgroup analyses of the 114 patients who received diphenhydramine during hospitalization revealed that a total of 237 doses were administered (Table 4). Patients received a mean of 2.1 doses, with 97\% of dose administered orally. The maximum cumulative daily dose for any given patient was $100 \mathrm{mg}$. Indications for diphenhydramine use (Table 5) included sleep (68\%), prophylaxis prior to blood transfusion (21\%), and therapy for allergic reactions or pruritus (3\%). Of the 50 diphenhydramine doses given for prophylaxis prior to blood transfusion, none were for an appropriate indication, ie, prior transfusion reaction. Other contraindications, specifically obstructive urinary symp- 
Table 1. Patient Characteristics at Baseline*

\begin{tabular}{|c|c|c|c|}
\hline Characteristic & $\begin{array}{l}\text { Diphenhydramine-Exposed Group } \\
\qquad(\mathrm{n}=114)\end{array}$ & $\begin{array}{l}\text { Diphenhydramine-Nonexposed Group } \\
\qquad(\mathrm{n}=312)\end{array}$ & $P$ Value \\
\hline Mean \pm SD age, $y$ & $80.3 \pm 5.6$ & $79.6 \pm 6.4$ & .29 \\
\hline Sex, male & $48(42)$ & $119(38)$ & .46 \\
\hline Race, white & $101(89)$ & $261(84)$ & .21 \\
\hline \multicolumn{4}{|l|}{ Admitted from } \\
\hline Home & $107(94)$ & $288(92)$ & .86 \\
\hline Nursing home & $6(5)$ & $21(7)$ & \\
\hline Mean \pm SD APACHE II score & $15.6 \pm 4.2$ & $15.6 \pm 4.1$ & .97 \\
\hline \multicolumn{4}{|l|}{ Baseline delirium risk $†$} \\
\hline Intermediate & $87(76)$ & $220(71)$ & .24 \\
\hline High & $27(24)$ & $92(29)$ & \\
\hline Mean \pm SD MMSE score & $23.6 \pm 4.7$ & $23.0 \pm 5.0$ & .29 \\
\hline Mean \pm SD No. of medications prior to admission & $5.4 \pm 3.1$ & $5.6 \pm 3.2$ & .46 \\
\hline Any impairment in ADLsł & $28(25)$ & $70(22)$ & .64 \\
\hline Mean \pm SD No. of diagnoses & $8.0 \pm 2.8$ & $7.5 \pm 2.8$ & .11 \\
\hline Baseline sleeping difficulty§ & $55(50)$ & $141(46)$ & .50 \\
\hline
\end{tabular}

*All data represent number (percentage) of patients unless otherwise indicated. APACHE II indicates Acute Physiology and Chronic Health Evaluation II; MMSE, Mini-Mental State Examination; and ADLs, activities of daily living.

†According to previously developed risk stratification system for delirium. ${ }^{23}$

łActivities of daily living include 7 basic-care skills: feeding, bathing, grooming, dressing, using the toilet, transferring between bed and chair, and walking.

$\S$ Self-report from admission interview; the sample size was slightly smaller owing to nonresponse of 4 patients in the diphenhydramine-exposed group and 7 patients in the diphenhydramine-nonexposed group.

\section{Table 2. Potential Adverse Outcomes Associated With Diphenhydramine Use*}

\begin{tabular}{|c|c|c|c|}
\hline Outcome & $\begin{array}{l}\text { Diphenhydramine-Exposed Group } \\
\qquad(\mathrm{n}=114)\end{array}$ & $\begin{array}{l}\text { Diphenhydramine-Nonexposed Group } \\
\qquad(\mathrm{n}=312)\end{array}$ & RR, $95 \%$ Cl \\
\hline \multicolumn{4}{|l|}{ Cognitive outcomes } \\
\hline Delirium symptomst & $47(42)$ & $75(24)$ & $1.7,1.3-2.3 \neq$ \\
\hline CAM delirium criteria & $9(8)$ & $12(4)$ & $2.1,0.9-4.7$ \\
\hline CAM delirium criteria or MMSE decline $\geq 3$ points & $16(14)$ & $25(8)$ & $1.8,1.0-3.2$ \\
\hline Inattention & $15(13)$ & $14(5)$ & $3.0,1.5-5.9 \neq$ \\
\hline Disorganized speech & $4(4)$ & $2(1)$ & $5.5,1.0-29.8$ \\
\hline Altered consciousness & $17(15)$ & $15(5)$ & $3.1,1.6-6.1 \neq$ \\
\hline Disorientation & $11(10)$ & $18(6)$ & $1.7,0.8-3.5$ \\
\hline Memory impairment & $8(7)$ & $15(5)$ & $1.5,0.6-3.4$ \\
\hline Perceptual disturbances & $2(2)$ & 0 & NA \\
\hline Abnormal psychomotor activity & $13(12)$ & $16(5)$ & $2.3,1.1-4.5 \ddagger$ \\
\hline Altered sleep-wake cycle & $22(22)$ & $32(11)$ & $2.0,1.2-3.3 \neq$ \\
\hline \multicolumn{4}{|l|}{ Other anticholinergic outcomes } \\
\hline Behavioral disturbance & $4(4)$ & $2(0.6)$ & $5.6,1.0-29.9 \neq$ \\
\hline Use of physical restraints & $2(2)$ & $2(0.7)$ & $2.8,0.4-19.4$ \\
\hline New urinary catheter & $9(8)$ & $10(3)$ & $2.5,1.0-6.0 \ddagger$ \\
\hline \multicolumn{4}{|l|}{ General outcomes } \\
\hline Median length of stay range, $d$ & $7(3-60)$ & $6(3-45)$ & $\ldots \S$ \\
\hline Length of stay $>7 d$ & $55(48)$ & $117(38)$ & $1.3,1.0-1.6 \neq$ \\
\hline
\end{tabular}

*All data represent number (percentage) of patients unless otherwise indicated. RR indicates relative risk; $\mathrm{Cl}$, confidence interval; CAM, Confusion Assessment Method; MMSE, Mini-Mental State Examination; and NA, not applicable. Data for some variables were unavailable.

†Any 1 of 9 commonly accepted delirium symptoms detailed in "Cognitive Outcomes" subsection of the "Patients and Methods" section.

$\ddagger P<.05$ for this relative risk. For all other RR values, $P \geq .05$.

$\S P=.009$ nonparametric 1-way analysis of variance.

toms, were present during the administration of 6 doses (3\% of total doses). Overall, 56 (24\%) of 237 doses were given inappropriately (50 doses for transfusion prophylaxis and 6 doses to patients with obstructive urinary symptoms).

\section{COMMENT}

This study shows that diphenhydramine use in hospitalized elderly patients carries substantial risk. Diphenhydramine use was associated with significant risk of cogni- tive decline, behavioral disturbance, and urinary catheter placement, of which the latter 2 may be markers of the anticholinergic effects of delirium resulting in agitation and urinary retention. In addition, a dose-response relationship was demonstrated for many of these adverse outcomes, and length of stay was significantly longer. Finally, diphenhydramine was inappropriately administered to $24 \%$ of patients. This study represents, to our knowledge, the largest and most detailed prospective cohort study in older patients that examines cognitive and other adverse outcomes following diphenhydramine use. 


\begin{tabular}{|c|c|c|c|c|}
\hline \multirow[b]{2}{*}{ Outcome } & \multicolumn{3}{|c|}{ Diphenhydramine Dose } & \multirow[b]{2}{*}{$P$ Valuef } \\
\hline & $\begin{array}{l}\geq 50 \mathrm{mg} \\
(\mathrm{n}=43)\end{array}$ & $\begin{array}{c}25 \mathrm{mg} \\
(\mathrm{n}=71)\end{array}$ & $\begin{array}{c}\text { No DPH } \\
(n=312)\end{array}$ & \\
\hline \multicolumn{5}{|l|}{ Cognitive outcomes } \\
\hline Delirium symptoms $\ddagger$ & $16(38)$ & $31(44)$ & $75(24)$ & .002 \\
\hline CAM delirium criteria & $4(10)$ & $5(7)$ & $12(4)$ & .07 \\
\hline CAM delirium criteria or MMSE decline $\geq 3$ points & $7(17)$ & $9(13)$ & $25(8)$ & .05 \\
\hline Inattention & $6(14)$ & $9(13)$ & $14(5)$ & .002 \\
\hline Disorganized speech & 0 & $4(6)$ & $2(1)$ & .26 \\
\hline Altered consciousness & $8(19)$ & $9(13)$ & $15(5)$ & .001 \\
\hline Disorientation & $3(7)$ & $8(11)$ & $18(6)$ & .31 \\
\hline Memory impairment & $1(2)$ & $7(10)$ & $15(5)$ & .82 \\
\hline Perceptual disturbances & 0 & $2(3)$ & 0 & .17 \\
\hline Abnormal psychomotor activity & $6(14)$ & $7(10)$ & $16(5)$ & .01 \\
\hline Altered sleep-wake cycle & $10(26)$ & $12(19)$ & $32(11)$ & .003 \\
\hline \multicolumn{5}{|l|}{ Other anticholinergic outcomes } \\
\hline Behavioral disturbance & $1(2)$ & $3(4)$ & $2(1)$ & .08 \\
\hline Use of physical restraints & 0 & $2(3)$ & $2(1)$ & .68 \\
\hline New urinary catheter & $2(5)$ & $7(10)$ & $10(3)$ & .15 \\
\hline \multicolumn{5}{|l|}{ General outcomes } \\
\hline Median length of stay (minimum-maximum), $d$ & $8(3-60)$ & $7(3-54)$ & $6(3-45)$ & $.03 \S$ \\
\hline Length of stay $>7 d$ & $22(51)$ & $33(46)$ & $117(38)$ & .04 \\
\hline
\end{tabular}

*All data represent number (percentage) of patients unless otherwise indicated. CAM indicates Confusion Assessment Method; MMSE, Mini-Mental State Examination. Data for some variables were unavailable.

$\dagger \chi^{2}$ trend statistic.

$\ddagger$ Any 1 of 9 commonly accepted delirium symptoms detailed in "Cognitive Outcomes" subsection of the "Patients and Methods" section.

$\S$ Nonparametric 1-way analysis of variance.

\section{Table 4. Description of Diphenhydramine Use}

\begin{tabular}{lc}
\hline Diphenhydramine Use & No. (\%) \\
\hline By patient* $(n=114)$ & \\
Cumulative doses received during hospitalization & \\
1 & $59(52)$ \\
2 & $26(23)$ \\
3 & $12(11)$ \\
$\geq 4$ & $17(15)$ \\
Maximum consecutive days of use & \\
1 & $76(67)$ \\
2 & $23(20)$ \\
3 & $8(7)$ \\
4 & $6(5)$ \\
5 & 0 \\
6 & $1(1)$ \\
By dose (n=237 doses) & \\
Dose route & \\
Intravenous & $6(2.5)$ \\
By mouth & $230(97)$ \\
Unknown & $1(0.5)$ \\
No. of 25-mg doses administered & $154(65)$ \\
No. of $\geq 50-m g$ doses administered & $83(35)$ \\
\hline
\end{tabular}

*Mean $\pm \mathrm{SD}$ number of doses per patient, $2.1 \pm 1.6$.

The delirium symptoms reported in this study likely capture more subtle and partial forms of delirium that do not meet full delirium criteria. The CAM criteria were limited to a 1-time observation, whereas the recognition of these delirium symptoms allowed the detection of more subtle changes in cognitive functioning over any 48-hour period following diphenhydramine exposure. The

\begin{tabular}{|c|c|}
\hline Diphenhydramine Use & $\begin{array}{c}\text { No. }(\%) \text { of Doses } \\
(\mathrm{n}=237)\end{array}$ \\
\hline \multicolumn{2}{|l|}{ Indications } \\
\hline Sleep & $162(68)$ \\
\hline Prophylaxis for blood transfusion* & $50(21)$ \\
\hline Allergic reaction or pruritis & $7(3)$ \\
\hline Preprocedure (cardiac catheterization) & $4(2)$ \\
\hline Agitation & $1(<1)$ \\
\hline Not documented & $13(6)$ \\
\hline \multicolumn{2}{|l|}{ Contraindications } \\
\hline Obstructive urinary symptoms & $6(3)$ \\
\hline
\end{tabular}

*All 50 doses administered to patients without documented prior transfusion reaction.

prognostic importance of these partial forms of delirium has been demonstrated in previous studies. ${ }^{26,27}$

This study documents that therapy with this widely used sedative-type medication (diphenhydramine) leads to substantial morbidity in older patients. Given its contribution to cognitive and anticholinergic adverse outcomes, the use of diphenhydramine as a routine sleep aid (the most common indication seen in our cohort) should be discouraged. This study lends strong support to a previously published expert consensus report on inappropriate medication use in the elderly, which deemed that diphenhydramine was inappropriate for use as a sedative in the elderly, independent of patient diagnosis. ${ }^{28} \mathrm{~A}$ thorough patient history, physical examination, and review of proper sleep hygiene is the recommended clini- 
cal workup, and therapy using nonpharmacologic intervention is the preferred management. ${ }^{29}$ Our results suggest that the clinician's review of a patient's list of daily medications to remove the "routine" or "as needed for sleep" prescriptions is critically important in reducing unwanted outcomes such as cognitive decline.

Another finding with important implications for inpatient physicians concerns the administration of diphenhydramine for routine transfusion prophylaxis. In the absence of a documented transfusion reaction, this therapy carries with it the risk of increased patient morbidity without documented benefit, and its practice has been widely discouraged. The 50 diphenhydramine doses administered with transfusion in this study were all administered inappropriately. Although it is possible that patients notified house staff about previous transfusion reactions, which led to diphenhydramine administration immediately prior to transfusion, the medical records did not support such occurrences.

This study derived strength from the prospective cohort design that provided precise data on exposures, eliminated recall bias, and provided carefully documented outcomes from daily interviews. In addition, wellaccepted, validated cognitive instruments were used as part of comprehensive daily assessments to determine the presence of cognitive impairment. Furthermore, we took careful steps to ensure that the temporal precedence of diphenhydramine administration and subsequent delirium was clearly documented.

Because the precise temporal correlation between diphenhydramine administration and onset of delirium or other adverse outcomes has not been clearly studied, we used a period of 48 hours for this study. A prior study documented a diphenhydramine elimination half-life of more than 13 hours in elderly patients, ${ }^{30}$ supporting our use of 48 hours after administration as a reasonable time frame in which to look for cognitive outcomes, particularly because the clinical components of acute confusion may last for days or longer.

One limitation of this study was the difficulty in controlling for other concurrently administered pharmacotherapies during hospitalization. However, there were no other sedative and/or hypnotic medications similar to diphenhydramine that were administered to such a large group, partly because of the hospital formulary's restriction on the use of drugs of this class at the institutional setting of this study. Further study of similar medications would prove valuable. In addition, our study site in a large teaching hospital with house staff may not reflect the prescribing patterns of community hospital physicians, although we believe that the practice of inhospital diphenhydramine administration is likely similar throughout the country. To address the potential for indication bias, we examined several comorbidity measures that were demonstrated to be well-balanced between our study groups. While acknowledging the potential for other sources of indication bias (eg, patients requiring transfusion may have been at higher risk for delirium), the careful examination of important baseline differences in risk (including comorbidity, baseline insomnia, and other patient characteristics) mitigated against such bias.
New bladder catheterization serves as an imperfect marker for acute urinary retention; however, given the importance of anticholinergic effects in older patients, we believed that this was a key area to examine. Even if the sensitivity of placement of a bladder catheter is low for the presence of urinary retention as an anticholinergic effect, catheterization in itself is still a risk factor for acute confusional state in older patients. ${ }^{8}$ Moreover, our study did not attempt to record all instances of straight catheterization (nonindwelling catheterization) for urinary retention, which may have minimized the exposed cohort's already significantly increased use of catheters. Further underestimation of the difference in risk of catheterization between the 2 study groups is possible because the risk period for nonexposed patients was the entire length of stay in contrast to the 48-hour period for the diphenhydramineexposed patients. Ideally, to document the adverse effects of diphenhydramine use, whether they be anticholinergic symptoms or confusion, a rechallenge would have been warranted, but ethical considerations precluded this.

Ultimately, appropriate use of diphenhydramine in the elderly remains an important clinical issue, not only because it is widely prescribed in older hospitalized patients, but also because it is present in a vast array of overthe-counter preparations and is used frequently in skilled nursing facilities. Thus, the magnitude of diphenhydramine use demands that clinicians carefully consider the potential for adverse outcomes in a population that is already at high risk based on age, baseline cognitive impairment, and other medical comorbidities.

\section{CONCLUSIONS}

In summary, this study suggests that diphenhydramine use in the hospitalized older patient contributes most notably to cognitive decline, behavioral disturbance, and initiation of bladder catheterization. Based on these data, we recommend that diphenhydramine be used with caution in elderly patients and not, for instance, administered as a routine sleep aid. Also, the practice of administering diphenhydramine prophylactically prior to blood transfusions in the absence of previous transfusion reaction has no documented benefit and should be curtailed. Increased attention to the potential for serious adverse effects in the elderly should lead to modification of common prescribing patterns and heightened awareness concerning the limited use of diphenhydramine in geriatric patients.

The applicability of this study to outpatients and inpatients in skilled nursing facilities requires further examination given the widespread use of diphenhydramine outside the hospital setting. Moreover, future studies are needed to address the cost savings of minimizing diphenhydramine use and its associated adverse outcomes as well as the benefits of minimizing hospital resources if complications resulting from iatrogenic medication use are reduced.

\section{Accepted for publication February 22, 2001.}

This study was funded in part by grant RO1AG12551 from the National Institute on Aging, Bethesda, Md, and received in-kind support by grant P60AG10469 from the 
Claude D. Pepper Older Americans Independence Center, Baltimore, Md. Dr Inouye is a recipient of a Midcareer Award from the National Institute on Aging (grant K24AG00949) and a Donaghue Investigator Award from the Patrick and Catherine Weldon Donaghue Medical Research Foundation, West Hartford, Conn (grant DF98-105).

Presented in part at the American Geriatrics Society/ American Federation for Aging Research Annual Scientific Meeting, Nashville, Tenn, May 18, 2000.

The authors would like to thank the Project Recovery staff, the Elder Life Program staff, and the patients and families at Yale-New Haven Hospital who participated in the study. We are indebted to Leo M. Cooney, Jr, MD, and Richard C. Lisitano, MS, RPh, for their contributions to this work and to Robbin Bonanno for her assistance.

Corresponding author and reprints: Sharon K. Inouye, MD, MPH, Yale University School of Medicine; Yale-New Haven Hospital, 20 York St, Tompkins 15, New Haven, CT 06504.

\section{REFERENCES}

1. Steel K, Gertman PM, Crescenzi C, Anderson J. latrogenic illness on a general medical service at a university hospital. N Engl J Med. 1981;304:638-642.

2. Cadieux RJ. Drug interactions in the elderly: how multiple drug use increases risk exponentially. Postgrad Med. 1989;86:179-186.

3. Tamblyn RM, McLeod PJ, Abrahamowicz M, et al. Questionable prescribing for elderly patients in Quebec. CMAJ. 1994;150:1801-1809.

4. Greenblatt DJ, Sellers EM, Shader RI. Drug disposition in old age. NEng/ J Med. 1982;306:1081-1088

5. Avorn J. Medications and the elderly. In: Rowe JW, Besdine RW, eds. Geriatric Medicine. 2nd ed. Boston, Mass: Little Brown \& Co Inc; 1988:114-121.

6. Larson EB, Kukull WA, Buchner D, Reifler B. Adverse drug reactions associated with cognitive impairment in elderly persons. Ann Intern Med. 1987;107:169-173.

7. Meader KJ. Cognitive side effects of medications. Neurol Clin. 1998;16:141155.

8. Inouye SK, Charpentier PA. Precipitating factors for delirium in hospitalized elderly persons. JAMA. 1996;275:852-857.

9. Feinberg M. The problems of anticholinergic adverse effects in older patients. Drugs Aging. 1993;3:335-348.

10. Beresin EV. Delirium in the elderly. J Geriatr Psychiatry Neurol. 1988;1:127143.

11. McEvoy GK, ed. American Hospital Formulary Service Drug Information 2000. Bethesda, Md: American Hospital Formulary Service; 2000.
12. Physicians'Desk Reference. 54th ed. Montvale, NJ: Medical Economics Co; 2000

13. Beers M, Avorn J, Soumerai SB, Everett DE, Sherman DS, Salem S. Psychoactive medication use in intermediate-care facility residents. JAMA. 1988;260: 3016-3020.

14. Marcantonio ER, Juarez G, Goldman L, et al. The relationship of postoperative delirium with psychoactive medications. JAMA. 1994;272:1518-1522.

15. Schor JD, Levkoff SE, Lipsitz LA, et al. Risk factors for delirium in hospitalized elderly. JAMA. 1992;267:827-831.

16. Francis J, Martin D, Kapoor WN. A prospective study of delirium in hospitalized elderly. JAMA. 1990;263:1097-1101.

17. Gustafson Y, Berggren D, Brannstrom B, et al. Acute confusional states in elderly patients treated for femoral neck fractures. J Am Geriatr Soc. 1988;36: 525-530

18. Lines C, Traub M, Raskin S, Mant T, Reines S. Lack of sedative and cognitive effects of diphenhydramine and cyclobenzaprine in elderly volunteers. J Psychopharmacol. 1997;11:325-329.

19. Sands L, Katz IR, DiFilippo S, D’Angelo K, Boyce A, Cooper T. Identification of drug-related cognitive impairment in older individuals: challenge studies with diphenhydramine. Am J Geriatr Psychiatry. 1997;5:156-166.

20. Tejera CA, Saravay SM, Goldman E, Gluck L. Diphenhydramine-induced delirium in elderly hospitalized patients with mild dementia. Psychosomatics. 1994; 35:399-402.

21. Folstein MF, Folstein SE, McHugh PR. "Mini-Mental State": a practical method for grading the cognitive state of patients for the clinician. J Psychiatr Res. 1975; 12:189-198.

22. Inouye SK, VanDyck CH, Alessi CA, Balkin S, Siegal AP, Horwitz RI. Clarifying confusion: the confusion assessment method. Ann Intern Med. 1990;113:941948.

23. Inouye SK, Viscoli CM, Horwitz RI, Hurst LD, Tinetti ME. A predictive model for delirium in hospitalized elderly medical patients based on admission characteristics. Ann Intern Med. 1993;119:474-481.

24. Charlson ME, Pompei P, Ales KL, MacKenzie CR. A new method of classifying prognostic comorbidity in longitudinal studies: development and validation. J Chronic Dis. 1987;40:373-383

25. Knaus WA, Draper EA, Wagner DP, Zimmerman JE. APACHE II: a severity of disease classification system. Crit Care Med. 1985;13:818-829.

26. Levkoff SE, Evans DA, Liptzin B, et al. Delirium: the occurrence and persistence of symptoms among elderly hospitalized patients. Arch Intern Med. 1992;152: 334-340.

27. Levkoff SE, Liptzin B, Evans DA, et al. Progression and resolution of delirium in elderly patients hospitalized for acute care. Am J Geriatr Psychiatry. 1994;2:230238.

28. Beers MH. Explicit criteria for determining potentially inappropriate medication use by the elderly: an update. Arch Intern Med. 1997;157:1531-1536.

29. McDowell JA, Mion LC, Lydon TJ, Inouye SK. A nonpharmacologic sleep protocol for hospitalized older patients. J Am Geriatr Soc. 1998;46:700-705.

30. Simons KJ, Watson WT, Martin TJ, Chen XY, Simons FE. Diphenhydramine: pharmacokinetics and pharmacodynamics in elderly adults, young adults, and children. J Clin Pharmacol. 1990;30:665-671. 